\title{
5-Hydroxymethylcytosine as a potential epigenetic biomarker in papillary thyroid carcinoma
}

\author{
MENGYING TONG ${ }^{1,2^{*}}$, SHUHANG GAO ${ }^{1 *}$, WENJING $\mathrm{QI}^{3 *}, \mathrm{CHANG} \mathrm{SHI}^{3}$, MENG QIU $^{1}$, FANG YANG $^{1}$,

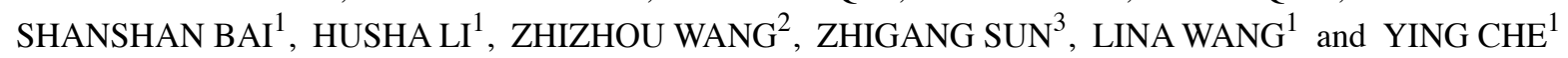 \\ ${ }^{1}$ Department of Ultrasound; ${ }^{2}$ Clinical Laboratory of Integrative Medicine; ${ }^{3}$ Department of Pathology, \\ The First Affiliated Hospital of Dalian Medical University, Dalian, Liaoning 116044, P.R. China
}

Received August 1, 2018; Accepted May 22, 2019

DOI: $10.3892 / \mathrm{ol} .2019 .10531$

\begin{abstract}
DNA methylation at the 5 position of cytosine $(5-\mathrm{mC})$ is an epigenetic hallmark that is critical in various biological and pathological processes such as DNA methylation regulation, and initiation and development of cancers. 5-mC can be oxidized to 5-hydroxymethylcytosine (5-hmC) by the ten-eleven translocation family of DNA hydroxylases. Accumulating evidence has reported that loss of $5-\mathrm{hmC}$ is associated with cancer development. However, its level in papillary thyroid carcinoma (PTC) remains unclear. The present study reports that the loss of $5-\mathrm{hmC}$ is an epigenetic mark of PTCs, associated with their malignant biological behavior, providing diagnostic and predictive advantages over DNA hypomethylation (5-mC), an acknowledged epigenetic alteration in cancer. In addition, the 5-hmC staining levels were decreased in cases of micro-carcinoma with lymph node metastasis, which suggests that 5-hmC expression levels could be used as valuable biomarkers for predicting malignant potential and assist in the selection of therapeutic strategies in PTC; therefore, 5-hmC has the potential to provide a more precise direction for PTC therapy.
\end{abstract}

\section{Introduction}

Thyroid cancer is a class of heterogeneous diseases that have various subtypes with different biological behaviors. Papillary thyroid carcinoma (PTC) is the most common subtype of thyroid cancer, and its incidence has been increasing considerably in recent years (1). A majority of PTCs are considered

Correspondence to: Dr Ying Che or Dr Lina Wang, Department of Ultrasound, The First Affiliated Hospital of Dalian Medical University, 222 Zhongshan Road, Dalian, Liaoning 116044,P.R. China E-mail: yche1964@163.com

E-mail: 510664072@qq.com

*Contributed equally

Key words: 5-hydoxymethylcytosine, biological marker, papillary thyroid carcinoma, epigenetics to have a good prognosis, whereas others may behave more aggressively (2). The risk stratification in patients with PTC has important clinical implications for the selection of therapeutic strategies. Therefore, novel biomarkers are urgently required for predicting the malignant potential of primary lesions and clinical outcome. To the best of our knowledge, the present study is the first to provide an epigenetic biomarker to help identify the differences between benign and malignant lesions and to assist in predicting their biological behaviors.

Epigenetic modifications serve a key role in numerous biological and pathological processes. DNA methylation at the 5 position of cytosine $(5-\mathrm{mC})$ acts as a key epigenetic marker that serves essential roles in genomic imprinting and regulation of gene expression (3). Aberrant DNA methylation is frequently observed in cancer. Hypermethylation of tumor suppressors and hypomethylation of oncogenes triggers tumorigenesis and tumor development (4). Disrupted DNA methylation patterns at the 5 position of cytosine have been substantiated as mechanism-based evidence in cancer (5). 5-mC can become oxidized to 5-hydroxymethylcytosine (5-hmC) by the ten-eleven translocation (TET) family of 5-mC hydroxylases, including TET1, 2 and 3 (6,7). Accumulating evidence has suggested that loss of 5-hmC is an epigenetic hallmark in various types of cancer, with diagnostic and prognostic implications (5,8-10). Aberrant methylation of various candidate genes have been reported potentially associated with thyroid carcinogenesis (11). However, the role of 5-hmC with regard to thyroid cancer remains largely unknown. In the present study, it was observed that the global level of 5-hmC is significantly decreased in PTC compared with benign thyroid disease. Furthermore, 5-hmC reduction is associated with potential malignant biological behavior, contributing to our present understanding of thyroid cancer epigenetics.

\section{Materials and methods}

Ethics statement. Thyroid cancer and nodular goiter samples were obtained from the archives of the Pathology Department of the First Affiliated Hospital of Dalian Medical University (Dalian, China), following the approval of the institutional review board. The Committee of Research Ethics waived the requirement of informed consent for the tissue sections used in this study, as patient data were anonymized. 
Patient cohorts and tissue samples. Cancer tissue and adjacent matching healthy tissue samples from 88 patients with PTC and 20 patients with nodular goiter (NG) treated at the First Affiliated Hospital of Dalian Medical University (Dalian, China) between January 2015 and September 2017 were included in the present study. The cohort had an age range of 23-75 years with 26 males and 82 females. All tissue sections were reviewed by an expert pathologist for verification of the clinical diagnosis. Each tissue sample had at least three independent tissue sections for the following analyses.

Immunohistochemistry (IHC) staining. IHC was employed to analyze $5 \mathrm{~mm}$ tissue sections, which had been fixed in $10 \%$ formalin for $24 \mathrm{~h}$ at room temperature and paraffin-embedded. Sections were dewaxed and rehydrated following standard protocols (12). Subsequently, antigen retrieval was performed by boiling the sections for $5 \mathrm{~min}$ in citric acid. The sections were dipped in the endogenous peroxidase blocker (cat. no. PV-6000D; OriGene Technologies, Inc., Beijing, China) for $10 \mathrm{~min}$ at room temperature. For immunolabeling of 5-hmC and 5-mC, a rabbit monoclonal 5-hydroxymethylcytosine antibody (cat. no. ab214728; Abcam, Cambridge, UK) and a mouse monoclonal 5-methylcytosine antibody (cat. no. ab10805; Abcam) were applied at 1:200 and 1:100 dilution, respectively for $1 \mathrm{~h}$ at room temperature. After the sections were washed with PBS, they were incubated with peroxidase-conjugated anti-rabbit/mouse immunoglobulin $\mathrm{G}$ (cat. no. PV-6000D; OriGene Technologies, Inc.; undiluted) at room temperature for $20 \mathrm{~min}$, followed by DAB chromogenic reaction performed according to the protocol of the DAB chromogenic reagent kit (cat. no. ZLI-9019; OriGene Technologies, Inc.). The sections were then counterstained with hematoxylin at room temperature for $1 \mathrm{~min}$, dehydrated with graded alcohol and xylene, and mounted onto coverslips. The stained cell images were captured under the light microscope (Olympus, Tokyo, Japan), and cells were counted and assessed at a magnification of X100.

Scoring system. Immunoreactivity of the nucleus was evaluated for each tissue section. In the case of NG, sections that indicated strong immunostaining in follicular cell nuclei were further evaluated. In the case of PTC, adjacent non-neoplastic cells were used as internal controls to evaluate the immunoreactivity. Thereafter, the H-score system was applied to evaluate positive immunoreactivity (9). Briefly, nuclei staining intensity $(0,1,2$ or 3$)$ was first determined for each cell in a fixed field corresponding to the presence of negative, weak, intermediate and strong staining, respectively. The percentage of cells at each staining intensity level was subsequently calculated, and an H-score (0-300) was assigned using the following formula: $\mathrm{H}$-score $=0 \times(\%$ of cells staining 0$)+1 \times(\%$ of cells staining 1$)$ $+2 \times(\%$ of cells staining 2$)+3 \times(\%$ of cells staining 3$)$. $\mathrm{H}$-scores for each case were calculated as the mean score of at least three individual section scores for each case, from which the mean score of all the individual field scores of each section was derived. In total 330 sections across 108 samples were analyzed.

Statistical analysis. The data are presented as either median \pm interquartile range or the mean \pm standard deviation
Table I. Clinical characteristics of NG and PTC cohort.

\begin{tabular}{|c|c|c|c|}
\hline Parameter & $\begin{array}{c}\mathrm{NG}(\%) \\
\mathrm{n}=20\end{array}$ & $\begin{array}{c}\mathrm{PTC}(\%) \\
\mathrm{n}=88\end{array}$ & $\begin{array}{l}\text { P-value } \\
\left(\chi^{2} \text { test }\right)\end{array}$ \\
\hline Age at surgery (years) & & & 0.354 \\
\hline$<50$ & $8(40)$ & $48(54.5)$ & \\
\hline$\geq 50$ & $12(60)$ & $40(45.5)$ & \\
\hline $\operatorname{Sex}(\%)$ & & & 0.329 \\
\hline Male & $7(35)$ & 19 (21.6) & \\
\hline Female & $13(65)$ & $69(78.4)$ & \\
\hline Nodule size, $\mathrm{cm}$ & & & 0.068 \\
\hline$\leq 1$ & $6(30)$ & $49(55.7)$ & \\
\hline$>1$ & $14(70)$ & $39(44.3)$ & \\
\hline Location & & & 0.183 \\
\hline Left lobe & $7(35)$ & $48(54.5)$ & \\
\hline Right lobe & $13(65)$ & $40(45.5)$ & \\
\hline
\end{tabular}

PTC, papillary thyroid carcinoma; NG, nodular goiter.

and were analyzed using GraphPad Prism 7.00 software (GraphPad Software, Inc., La Jolla, CA, USA). The $\chi^{2}$ test was used to analyze differences of clinical parameters between two groups of patients. A Student's t-test was used to analyze differences in 5-hmC level (H-scores). Pearson or Spearman's rank correlation analysis was used to evaluate the correlation between 5 -hmC level and pathological parameters. $\mathrm{P}<0.05$ was considered to indicate a statistically significant difference.

\section{Results}

5-hmC expression level is high in NG and lost in PTC. To evaluate the global 5-hmC landscape, 5-hmC levels in the thyroid tissues were examined by IHC staining with a specific anti-5-hmC antibody in two representative cohorts (Table I), including PTC $(n=88)$ and NG $(n=20)$. IHC analysis of NG tissues indicated robust 5-hmC staining of the nucleus, whereas the cancer cells in PTC tissues exhibited reduced 5-hmC staining by comparison (Fig. 1A). The H-scoring indicated that the 5-hmC level was significantly decreased in PTC tissues compared with NG tissues $(\mathrm{P}<0.0001$; Fig. 1B). Low nuclear 5-hmC staining was also observed in thyroid cancer tissues compared with the adjacent non-neoplastic tissues (Fig. 1C and D). However, there was no difference in 5-mC levels between NG and PTC, as well as cancer and adjacent normal tissue (Fig. 2). These data indicate that a high level of 5-hmC is a distinct epigenetic signature in benign thyroid disease, and a significant loss of 5-hmC is a distinctive hallmark of thyroid cancer. In addition, the 5-hmC level has a more sensitive diagnostic value compared with 5-mC in PTC.

5-hmC is a useful molecular hallmark of potential PTC. 5-hmC levels between PTCs with lymph node metastases $\left(\mathrm{N}^{+}\right)$ and PTCs without lymph node metastases $\left(\mathrm{N}^{-}\right)$were analyzed by IHC in order to evaluate if 5-hmC level correlates with malignancy of PTC. H-score indicated that the 5-hmC level was significantly lower in PTCs with $\mathrm{N}^{+}(\mathrm{n}=45)$ compared with 
A

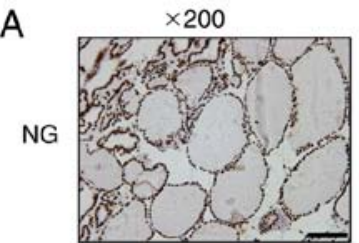

TC

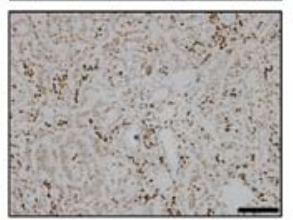

C

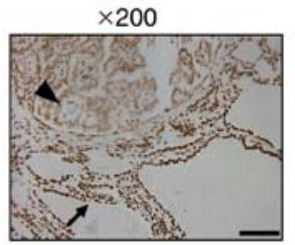

$\times 400$

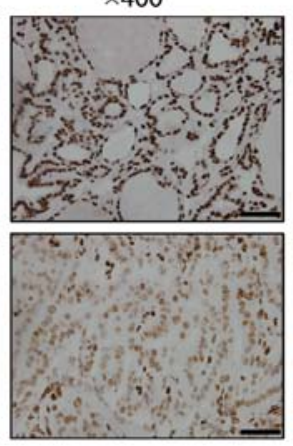

$\times 400$

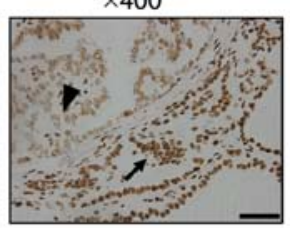

B
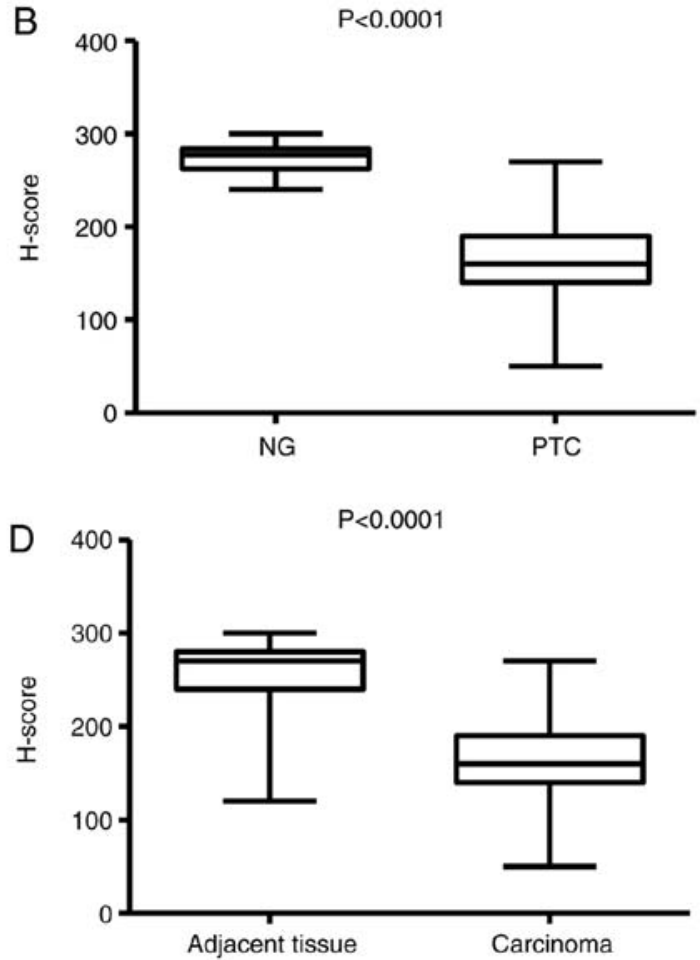

Figure 1. The level of 5-hmC is reduced in PTC. (A) Representative histology for immunohistochemistry staining of 5-hmC in representative cases of benign and malignant thyroid disease. (B) Boxplot depicting 5-hmC H-score distribution in patients with NG ( $\mathrm{n}=20)$ and PTC ( $\mathrm{n}=88$ ). Each case has duplicated tissue cores. (C) Normal thyroid follicular epithelium indicates strong nuclear 5-hmC staining (arrow); cancer cells exhibit reduced staining intensities (arrowhead). (D) Boxplot depicting 5-hmC H-score distribution in adjacent non-neoplastic tissue and carcinoma (n=88). Each case has duplicated tissue cores. The boxplot lines from top to bottom represent maximum, 75th percentile, median, 25th percentile and minimum, respectively. Magnification, $\mathrm{x} 200$; scale bar, $100 \mu \mathrm{m}$. Magnification, x400; scale bar, $50 \mu \mathrm{m}$. 5-hmC, 5-hydroxymethylcytosine; NG, nodular goiter; PTC, papillary thyroid carcinoma.

\section{A}
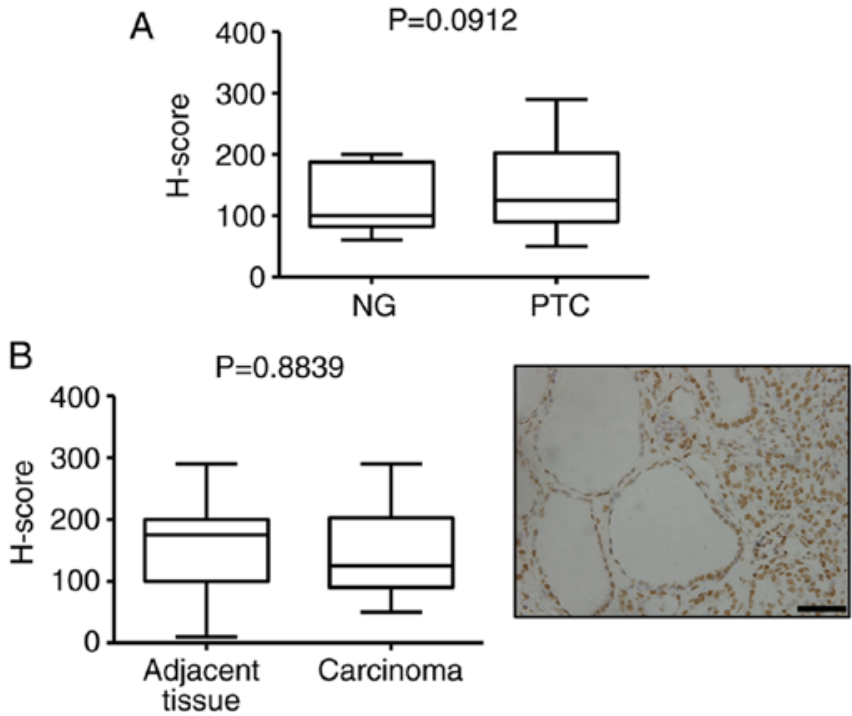

Figure 2. The level of 5-mC in PTC. (A) Boxplot depicting 5-mC H-score distribution in patients with NG $(n=20)$ and PTC $(n=30)$. (B) Boxplot indicating no significant difference between cancer and adjacent tissues $(n=30)$ (left). 5-mC staining of one representative field (right). The boxplot lines from top to bottom represent maximum, 75th percentile, median, 25th percentile and minimum, respectively. Scale bar, $50 \mu \mathrm{m}$. 5-mC, 5-methylcytosine; PTC, papillary thyroid carcinoma; NG, nodular goiter.

PTCs with $\mathrm{N}^{-}(\mathrm{n}=43 ; \mathrm{P}=0.0039 ;$ Fig. $3 \mathrm{~A}$ and $\mathrm{B})$. Consistently, there was a negative correlation between 5 -hmC staining and the number of metastatic lymph nodes, a predictor of malignant potential (Fig. 3A; $\mathrm{r}^{2}=0.2104 ; \mathrm{P}<0.0001$ ). A correlation analysis was subsequently conducted comparing the 5 -hmC level to tumor size (the largest diameter the tumor), with no correlation indicated, while the 5-hmC levels of micro-carcinomas with $\mathrm{N}^{+}$ $(n=22)$ were lower compared than those of macro-carcinomas with $\mathrm{N}^{-}(\mathrm{n}=21 ; \mathrm{P}=0.0086$; Fig. 3C). In addition, in the limited number of patients that exhibited tumor development during the follow-up duration (12-42 months), no significant correlation between cancer 5-hmC levels and cancer recurrence was indicated ( $\mathrm{P}=0.3679$; data not shown). Therefore, these results support the conclusion that a reduction in 5 -hmC serves as a distinctive epigenetic event in the initiation and progression of PTC, suggesting it may represent a novel epigenetic hallmark for PTC recognition and prediction of malignancy.

\section{Discussion}

DNA methylation is an essential epigenetic modification that is often altered in cancer (13). In general, global 5-mC reduction at specific sites of the genome is associated with cancer progression $(14,15)$. Current evidence suggests that the oxidation of 5-mC to 5-hmC serves a critical role in epigenetic plasticity (16-18). The family of TET enzymes are 5-methylcytosine oxidases that transform 5-mC to 5-hmC (19). $5-\mathrm{hmC}$ is a key intermediate of DNA demethylation that can affect global gene expression in mammals (20). A number of previous studies have reported that the amount of $5-\mathrm{hmC}$ is substantially decreased in various types of cancer, including in brain, lung, breast, liver, pancreatic, colon and prostate 
A
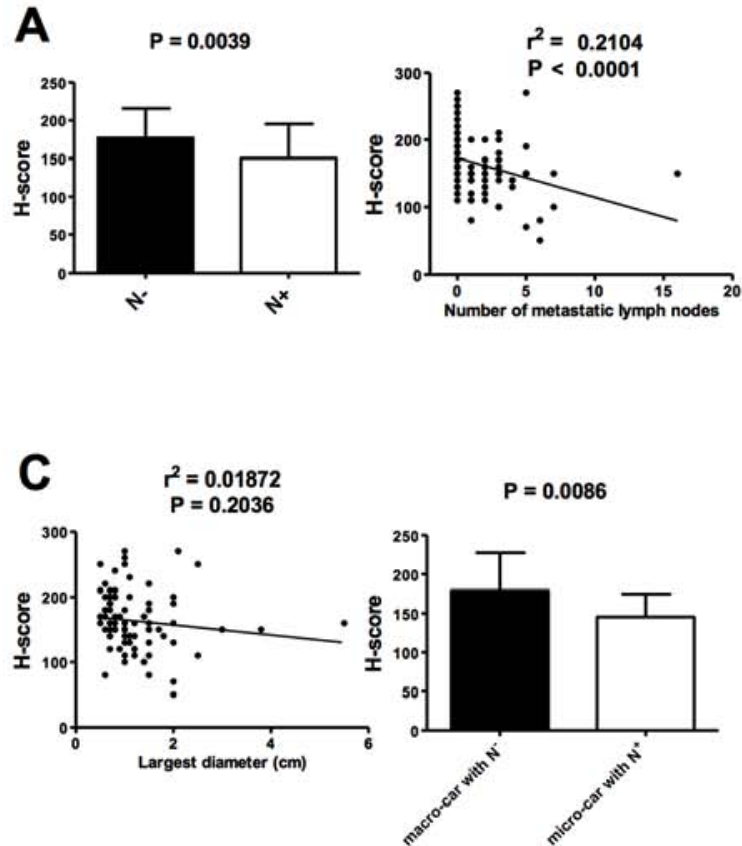

B

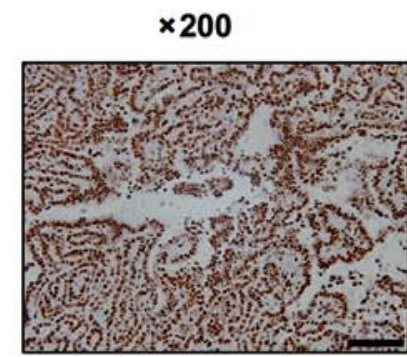

$\mathbf{N}^{+}$

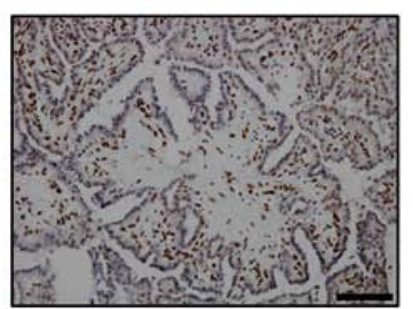

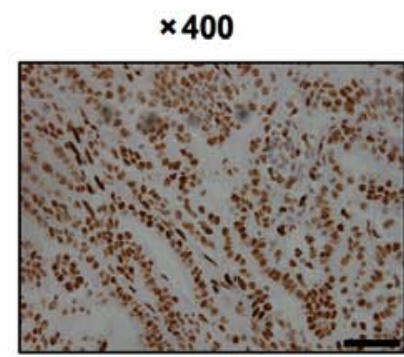

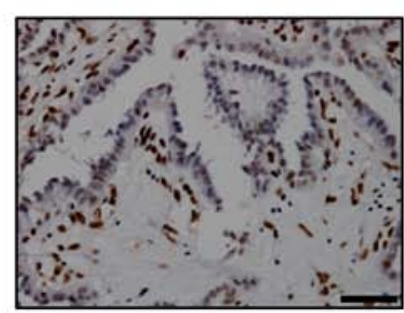

Figure 3. Loss of 5-hmC is associated with malignant potential of PTC. (A) Analysis of 5-hmC levels between PTCs with $\mathrm{N}^{+}(\mathrm{n}=45)$ and $\mathrm{N}^{-}(\mathrm{n}=43)$, represented by $\mathrm{H}$-score (left). Spearman correlation analysis between 5 -hmC staining and the number of metastatic lymph nodes (right). At least three tissue sections were analyzed for each case. (B) Representative IHC staining of 5-hmC in the individual cases of PTC with $\mathrm{N}^{-}$and PTC with $\mathrm{N}^{+}$. Left: Low-power images (magnification, x200); scale bars, $100 \mu \mathrm{m}$. Right: High-power images (magnification, x400); scale bar, $50 \mu \mathrm{m}$. (C) Pearson correlation analysis between 5 -hmC staining and tumor size (left). Analysis of 5-hmC levels between macro-carcinoma with $\mathrm{N}^{-}(\mathrm{n}=21)$ and micro-carcinoma with $\mathrm{N}^{+}(\mathrm{n}=22)$, represented by $\mathrm{H}$-score (right). At least three tissue sections were analyzed for each case. Data are presented as the mean \pm standard error. 5-hmC, 5-hydroxymethylcytosine; PTC, papillary thyroid carcinoma; 5- $\mathrm{N}^{+}$, lymph node metastases; $\mathrm{N}^{-}$, no lymph node metastases.

cancer, and myeloid leukemia (5,21-26). However, the 5-hmC level in PTC remains unknown. In the present study, it was indicated that reduced 5 -hmC is a characteristic epigenetic event in PTCs that is associated with malignant biological behavior. Given that 5 -hmC is oxidized from 5 -mC, and hypomethylation is an acknowledged epigenetic alteration in cancer (27), it was hypothesized that the underlying mechanism for the global decrease in 5-hmC levels in PTC is due to a reduction in 5-mC. However, it was indicated that 5-mC levels were similar between PTC and NG, therefore the mechanism is derived from the oxidation process rather than 5 -mC loss. As TET enzymes mediate the oxidation process of $5-\mathrm{mC}$ to $5-\mathrm{hmC}$, and partial or complete loss of $5-\mathrm{hmC}$ is frequently associated with significantly decreased expression of the three TET genes, suggesting a potential mechanism to explain the loss of 5-hmC in cancer cells (21). In addition, the catalytic oxidation reaction through TET enzyme requires the cofactor $\alpha$-ketoglutarate $(6,7)$, which is mainly controlled by isocitrate dehydrogenase (IDH). Therefore, understanding the role of 5-hmC, TET and IDH involved in PTC initiation and progression is crucial. Further examination of the underlying mechanism of this epigenetic marker is required, in addition to the role of the associated enzymes involved in PTC.

PTC is a unique cancer, and the prognosis varies widely. PTCs measuring $<10 \mathrm{~mm}$ at the largest diameter are termed micro-carcinomas (28). Due to the advent of high-resolution ultrasound detection and increasing regular fine-needle aspiration biopsies, the incidence of micro-carcinomas has increased worldwide (29). Micro-carcinomas are often considered as indolent tumors and have a good prognosis; however, a small proportion of these tumors are capable of metastasizing when the volume of the original tumor is estimated to be as little as $1 \mathrm{~mm}^{3}(29)$. Accumulating evidence indicates that surgical excision is not recommended for micro-carcinomas, particularly indolent micro-carcinomas $(30,31)$. Radiof requency ablation can effectively eliminate low-risk micro-carcinomas with a low complication rate $(32,33)$. Therefore, distinguishing aggressive from indolent micro-carcinomas has important clinical implications for the selection of therapeutic strategies. Current routine characteristics, based on clinical assessment and pathology, cannot explicitly distinguish aggressive from indolent PTCs at an early phase (34), and, therefore, uncovering novel prognostic biomarkers is required. In the present study, it was indicated that 5 -hmC expression levels in micro-carcinomas with metastasis (high risk) is lower compared with macro-carcinomas without metastasis (low risk), which suggests that the level of 5-hmC may serve as a valuable biomarker for predicting the malignant potential of PTC and assist in the selection of therapeutic strategies.

This study also endeavors to evaluate the patients' survival data by directly associating the low 5-hmC levels with PTC prognosis. However, recurrence of PTC following optimized surgery is uncommon, and the latent durations prior to detection of distant and lethal metastases may vary from years to decades (35). The follow-up duration of the current study is not long enough to observe the prognostic value of 5-hmC in PTC. Studies of hallmarks used for predicting clinical outcome of thyroid cancer also have this limitation, as investigation is hindered by the barriers of the follow-up interviews. Consequently, clinically annotated biospecimen archives can serve as valuable substitutes for theoretical and impractical prospective strategies. 
The present study demonstrates that global 5-hmC levels are greatly diminished in the majority of PTCs. Ongoing mechanistic investigations and identification of target genes through comprehensive genome-wide mapping will shed further light on cancer epigenetics (5,36-38). In the present study, 5-hmC loss in PTC was a basic epigenetic event that suggested that fundamental molecules in the 5-hmC biological pathway can be therapeutically targeted to re-establish the level of 5-hmC, and therefore reveal novel approaches in the therapy of aggressive PTC. With the significance of clinical therapeutics, the current study provides a novel direction for cancer prevention and treatment, by targeting the cellular molecules and biochemical pathways that restore the landscape of 5-hmC in PTC.

\section{Acknowledgements}

The authors acknowledge Dr Shuang Li from the Clinical Laboratory of Integrative Medicine of the First Affiliated Hospital of Dalian Medical University (Dalian, China) and Dr Yandong Zhang from the Chinese Academy of Medical Sciences for their help with IHC staining processing, and Dr Liang Wang from the Central Laboratory of the First Affiliated Hospital of Dalian Medical University for the helpful comments.

\section{Funding}

The present study was funded by The Natural Science Foundation of Liaoning Province (grant no. 201602221; Dalian, China).

\section{Availability of data and materials}

The datasets used and/or analyzed during the present study are available from the author on reasonable request.

\section{Authors' contributions}

MT, SG and WQ performed experiments, analyzed the data and wrote the paper. MQ, ZS, CS, ZW, FY, HL and SB carried out additional analyses and supported the study. YC and LW jointly designed, oversaw and directed the study. All authors read and approved the final version of this manuscript.

\section{Ethics approval and consent to participate}

Thyroid cancer and nodular goiter samples were obtained from the archives of the Pathology Department of the First Affiliated Hospital of Dalian Medical University (Dalian, China) following the approval of the committee of research ethics. The committee of research ethics of the First Affiliated Hospital of Dalian Medical University (Dalian, China) waived the requirement of informed consent for the tissue sections used in this study as patient data were anonymized.

\section{Patient consent for publication}

Not applicable

\section{Competing interests}

The authors declare that they have no competing interests.

\section{References}

1. Vigneri R, Malandrino $P$ and Vigneri P: The changing epidemiology of thyroid cancer: Why is incidence increasing? Curr Opin Oncol 27: 1-7, 2015.

2. Mazeh $\mathrm{H}$ and Chen $\mathrm{H}$ : Advances in surgical therapy for thyroid cancer. Nat Rev Endocrinol 7: 581-588, 2011.

3. Suzuki MM and Bird A: DNA methylation landscapes: Provocative insights from epigenomics. Nat Rev Genet 9: 465-476, 2008.

4. Wu YC and Ling ZQ: The role of TET family proteins and 5-hydroxymethylcytosine in human tumors. Histol Histopathol 29: 991-997, 2014.

5. Lian CG, Xu Y, Ceol C, Wu F, Larson A, Dresser K, Xu W, Tan L, Hu Y, Zhan Q, et al: Loss of 5-hydroxymethylcytosine is an epigenetic hallmark of melanoma. Cell 150: 1135-1146, 2012.

6. Ito S, D'Alessio AC, Taranova OV, Hong K, Sowers LC and Zhang Y: Role of Tet proteins in $5 \mathrm{mC}$ to $5 \mathrm{hmC}$ conversion, ES-cell self-renewal and inner cell mass specification. Nature 466: 1129-1133, 2010.

7. Tahiliani M, Koh KP, Shen Y, Pastor WA, Bandukwala H, Brudno Y, Agarwal S, Iyer LM, Liu DR, Aravind L and Rao A: Conversion of 5-methylcytosine to 5-hydroxymethylcytosine in mammalian DNA by MLL partner TET1. Science 324: 930-935, 2009.

8. Liu X, Zhang G, Yi Y, Xiao L, Pei M, Liu S, Luo Y, Zhong H, $\mathrm{Xu}$ Y, Zheng W and Shen J: Decreased 5-hydroxymethylcytosine levels are associated with TET2 mutation and unfavorable overall survival in myelodysplastic syndromes. Leuk Lymphoma 54: 2466-2473, 2013.

9. MunariE,Chaux A,VaghasiaAM,TaheriD,KarramS,BezerraSM, Gonzalez Roibon N, Nelson WG, Yegnasubramanian S, Netto GJ and Haffner MC: Global 5-hydroxymethylcytosine levels are profoundly reduced in multiple genitourinary malignancies. PLoS One 11: e0146302, 2016.

10. Qiu L, Liu F, Yi S, Li X, Liu X, Xiao C, Lian CG, Tu P and Wang Y: Loss of 5-hydroxymethylcytosine is an epigenetic biomarker in cutaneous T cell lymphoma. J Invest Dermatol 138: 2388-2397, 2018.

11. Mancikova V, Buj R, Castelblanco E, Inglada-Pérez L, Diez A, de Cubas AA, Curras-Freixes M, Maravall FX, Mauricio D, Matias-Guiu X, et al: DNA methylation profiling of well-differentiated thyroid cancer uncovers markers of recurrence free survival. Int J Cancer 135: 598-610, 2014.

12. Paulsen IM,Dimke $H$ and Frische S: A single simple procedure for dewaxing, hydration and heat-induced epitope retrieval (HIER) for immunohistochemistry in formalin fixed paraffin-embedded tissue. Eur J Histochem 59: 2532, 2015.

13. Bhutani N, Burns DM and Blau HM: DNA demethylation dynamics. Cell 146: 866-872, 2011.

14. Esteller M: Epigenetics in cancer. N Engl J Med 358: 1148-1159, 2008.

15. Jones PA and Baylin SB: The epigenomics of cancer. Cell 128: 683-692, 2007.

16. Hemberger M, Dean W and Reik W: Epigenetic dynamics of stem cells and cell lineage commitment: Digging Waddington's canal. Nat Rev Mol Cell Biol 10: 526-537, 2009.

17. Kohli RM and Zhang Y: TET enzymes, TDG and the dynamics of DNA demethylation. Nature 502: 472-479, 2013.

18. Shen L and Zhang Y: 5-Hydroxymethylcytosine: Generation, fate, and genomic distribution. Curr Opin Cell Biol 25: 289-296, 2013.

19. Rasmussen KD and Helin K: Role of TET enzymes in DNA methylation, development, and cancer. Genes Dev 30: 733-750, 2016.

20. Li W, Zhang X, Lu X, You L, Song Y, Luo Z, Zhang J, Nie J, Zheng W, Xu D, et al: 5-Hydroxymethylcytosine signatures in circulating cell-free DNA as diagnostic biomarkers for human cancers. Cell Res 27: 1243-1257, 2017.

21. Yang H, Liu Y, Bai F, Zhang JY, Ma SH, Liu J, Xu ZD, Zhu HG, Ling ZQ, Ye D, et al: Tumor development is associated with decrease of TET gene expression and 5-methylcytosine hydroxylation. Oncogene 32: 663-669, 2013.

22. Haffner MC, Chaux A, Meeker AK, Esopi DM, Gerber J, Pellakuru LG, Toubaji A, Argani P, Iacobuzio-Donahue C, Nelson WG, et al: Global 5-hydroxymethylcytosine content is significantly reduced in tissue stem/progenitor cell compartments and in human cancers. Oncotarget 2: 627-637, 2011. 
23. Jin SG, Jiang Y, Qiu R, Rauch TA, Wang Y, Schackert G, Krex D, Lu Q and Pfeifer GP: 5-Hydroxymethylcytosine is strongly depleted in human cancers but its levels do not correlate with IDH1 mutations. Cancer Res 71: 7360-7365, 2011.

24. Kudo Y, Tateishi K, Yamamoto K, Yamamoto S, Asaoka Y, Ijichi H, Nagae G, Yoshida H, Aburatani H and Koike K: Loss of 5-hydroxymethylcytosine is accompanied with malignant cellular transformation. Cancer Sci 103: 670-676, 2012.

25. Ko M, Huang Y, Jankowska AM, Pape UJ, Tahiliani M, Bandukwala HS, An J, Lamperti ED, Koh KP, Ganetzky R, et al: Impaired hydroxylation of 5-methylcytosine in myeloid cancers with mutant TET2. Nature 468: 839-843, 2010.

26. Kraus TF, Globisch D, Wagner M, Eigenbrod S, Widmann D, Münzel M, Müller M, Pfaffeneder T, Hackner B, Feiden W, et al: Low values of 5-hydroxymethylcytosine $(5 \mathrm{hmC})$, the "sixth base,' are associated with anaplasia in human brain tumors. Int J Cancer 131: 1577-1590, 2012.

27. Kanwal R and Gupta S: Epigenetic modifications in cancer. Clin Genet 81: 303-311, 2012.

28. Zafon C, Baena JA, Castellvi J, Obiols G, Monroy G and Mesa J: Differences in the form of presentation between papillary microcarcinomas and papillary carcinomas of larger size. J Thyroid Res 2011: 639156, 2010.

29. Schneider DF and Chen H: New developments in the diagnosis and treatment of thyroid cancer. CA Cancer J Clin 63: 374-394, 2013.

30. Ito $Y$, Miyauchi A, Inoue H, Fukushima M, Kihara M, Higashiyama T, Tomoda C, Takamura Y, Kobayashi K and Miya A: An observational trial for papillary thyroid microcarcinoma in Japanese patients. World J Surg 34: 28-35, 2010.

31. Londero SC, Krogdahl A, Bastholt L, Overgaard J, Trolle W, Pedersen HB, Bentzen J, Schytte S, Christiansen P and Godballe C; Danish Thyroid Cancer Group: Papillary thyroid microcarcinoma in Denmark 1996-2008: A national study of epidemiology and clinical significance. Thyroid 23: 1159-1164, 2013.
32. Jeong SY, Baek JH, Choi YJ, Chung SR, Sung TY, Kim WG, Kim TY and Lee JH: Radiofrequency ablation of primary thyroid carcinoma: Efficacy according to the types of thyroid carcinoma. Int J Hyperthermia 34: 611-616, 2018.

33. Zhang M, Luo Y, Zhang Y and Tang J: Efficacy and safety of ultrasound-guided radiofrequency ablation for treating low-risk papillary thyroid microcarcinoma: A prospective study. Thyroid 26: 1581-1587, 2016.

34. Haugen BR, Alexander EK, Bible KC, Doherty GM, Mandel SJ, Nikiforov YE, Pacini F, Randolph GW, Sawka AM, Schlumberger M, et al: 2015 American thyroid association management guidelines for adult patients with thyroid nodules and differentiated thyroid cancer: The American thyroid association guidelines task force on thyroid nodules and differentiated thyroid cancer. Thyroid 26: 1-133, 2016.

35. Chereau N, Oyekunle TO, Zambeli-Ljepović A, Kazaure HS, Roman SA, Menegaux F and Sosa JA: Predicting recurrence of papillary thyroid cancer using the eighth edition of the AJCC/UICC staging system. Br J Surg 106: 889-897, 2019.

36. Figueroa ME, Abdel-Wahab O, Lu C, Ward PS, Patel J, Shih A, Li Y, Bhagwat N, Vasanthakumar A, Fernandez HF, et al: Leukemic IDH1 and IDH2 mutations result in a hypermethylation phenotype, disrupt TET2 function, and impair hematopoietic differentiation. Cancer Cell 18: 553-567, 2010.

37. Plongthongkum N, Diep DH and Zhang K: Advances in the profiling of DNA modifications: Cytosine methylation and beyond. Nat Rev Genet 15: 647-661, 2014.

38. ShimEH,Livi CB, Rakheja D, Tan J,Benson D, Parekh V, KhoEY, Ghosh AP, Kirkman R, Velu S, et al: L-2-Hydroxyglutarate: An epigenetic modifier and putative oncometabolite in renal cancer. Cancer Discov 4: 1290-1298, 2014.

This work is licensed under a Creative Commons Attribution-NonCommercial-NoDerivatives 4.0 International (CC BY-NC-ND 4.0) License. 